\title{
Finite elements analysis of an underground collector installed by pipe- jacking method
}

Luis María Díaz-Díaz ${ }^{1}$, Joshua Omer², Daniel Arias ${ }^{3}$

${ }^{1}$ Department of Geology, University of Oviedo, Oviedo, Spain. Jesús Arias de Velasco 33005 Oviedo (Spain). P.: 9851031 24.Imdiaz@geol.uniovi.es

${ }^{2}$ Natural \& Built Environments. Faculty of Science, Engineering and Computing, Kingston University, London, UK. Penrhyn Road, Kingston Upon Thames, Surrey KT1 2EE. P.: 44(0) 208417 2243. J.R.Omer@ kingston.ac.uk

${ }^{3}$ Department of Geology, University of Oviedo, Oviedo, Spain. Jesús Arias de Velasco 33005 Oviedo (Spain). P.: 9851031 09. darias@ geol.uniovi.es

Corresponding author: Luis María Díaz Díaz

Department of Geology, University of Oviedo. Jesús Arias de Velasco 33005 Oviedo (Spain). T.: 9851031 24.1mdiaz@geol.uniovi.es 


\title{
Finite elements analysis of an underground collector installed by pipe- jacking method
}

\author{
Using the commercial software $R S^{2}$, a 2D finite element program for soil and \\ rock application, the ground response to pipe jacking in pipeline installation in \\ Avilés (north coast of Spain) was analyzed. The geology of the location \\ comprises Quaternary deposits on both flanks of the Avilés estuary and includes \\ different highly variable geotechnical behavior. Both axi-symmetric and plane \\ strain analyses were carried out in $R S^{2}$ to simulate in $3 \mathrm{D}$ the ground response to \\ pipe advancement. The results demonstrate that the vertical displacements at \\ specific positions in the immediate vicinity of the pipeline were small. The \\ maximum deformation at ground surface was shown to be less than $1.5 \mathrm{~mm}$, \\ which was still safe. However the displacements were found to vary depending \\ on the local properties of the materials drilled. Stress distributions were also \\ computed.
}

Keywords: micro-tunnel; finite element analysis; pipe-jacking, Avilés

\section{Introduction and project description}

Pipe-jacking method is considered the finest current technique for installing underground pipelines such as micro-tunnels and conduits without trench excavation (Thompson, 1993; Bennet et al., 1995). This technique has several advantages over traditional excavation methods and is generally the most suitable technique for densely populated urban areas and for certain depths of operation (Díez López, 2001; Peila, 2001).

In jacking method, the pipeline is pushed horizontally behind a cutter head that drills through the ground simultaneously. Thus micro-tunneling is combined with the jacking system. The force required to propel the crown forward is provided by hydraulic jacks that operate against a wall thrust located in the jacking shaft (Evaraerts \& Docavo, 2007). During the cutting, concrete pipes are entered from the back of the cutter by the jack pressure until coming into contact with the reception shaft (Thompson, 1993). The 
cutter location is laser controlled by the operator housed in a cabin situated at the ground surface.

Although this method has many advantages, significant problems can be found advancing in different types of soils that possess highly variable geotechnical characteristics (Milligan \& Norris, 1996; Descoeudres \& Egger, 1993; Schotmeyer et al., 1999; Shou \& Chang, 2006). The use of underground machines may depend on the material since the presence of unexpected deposits might necessitate withdrawal and replacement of the excavation head (Oreste, 2002). This is the reason why accurate geological and geotechnical studies are crucial in such infrastructure projects. The cost of such studies can account for between $0.1 \%$ and $4 \%$ of the total project cost (Look, 2007).

In recent years, several studies have shown a prediction, analysis and control of environmental deformation by pipe jacking (Chapman, 1999; Senda et al., 2013; Farrel \& Terry, 2015; Cheng \& Lu., 2015; Cui et al., 2015; Shen et al., 2016). However, these projects are related with relatively simple environmental condition.

This article presents a useful analysis method for estimating simultaneously the stability, stress distribution and groundwater seepage as the pipeline is being advanced into the ground. The main objectives of this paper are: (i) to predict in $3 \mathrm{D}$ the ground response using the commercial 2D finite element software named $R S^{2}$ (supplied by Rocscience Ltd) and (ii) to show the possible patterns of ground subsidence and tunnel stresses to inform designers as to whether the tunnel will be stable and safe. The predictions made in this paper have the potential to help engineers avoid problems that can occur during drilling so that timely intervention is instituted to devise appropriate solutions. 
Figure 1 shows a map of the Avilés estuary and the pipeline alignment. Based on interpretation of the geological profile, 7 transverse sections were modeled with the $R S^{2}$ finite element software. The selection of these sections took into account potentially unstable zones, with low geotechnical strength parameters, where the pipeline depth exceeded $2 \mathrm{~m}$.

The research is mainly concerned with the results of a case study conducted on a project to create a long industrial collector of effluent network in the east bank of the river in the Avilés, northern Spain (Fig. 1). This coastal city has significant port and industrial installations in its environs. The industrial effluent network, constructed in the year 2010, has a length of $13.087 \mathrm{~km}$ and consists of $1.5 \mathrm{~m}$ diameter pipes, reaching a maximum depth of $5.8 \mathrm{~m}$ below the surface. Only the first $7.0 \mathrm{~km}$ of the collector (south area) were formed using pipe-jacking method whilst the rest were formed in open excavations or surface laid.

The ground within the pipe-jacked segment of the pipeline is characterized by the presence of both Mesozoic bedrock and Quaternary deposits (Fig. 1). Several geological surveys and geotechnical investigations carried out as part of the effluent collector project allowed the development of a geological profile and a quantitative geotechnical evaluation of all drilled materials. Furthermore, there have been various construction related developments within the underlying Quaternary deposits, which are heterogeneous in nature. Consequently, complex geotechnical problems have been experienced during civil engineering works in the above geo-materials.

\section{Geological setting}

The study area is located on the north-western fringes of the central Mesotertiary basin of Asturias (Julivert, 1967; Alonso et al., 2009). The bedrock is formed of 3 units: (a) Permo-triassic Unit (sandstones, clays and marls), (b) Carbonate Jurassic Unit and (c) 
Conglomeratic Jurassic Unit (Torres Alonso \& Gutiérrrez Claverol, 2005). These rocks overlie Paleozoic basement unconformably and are bedded sub-horizontally with a typical dip of $5-20^{\circ}$.

The development of Quaternary deposits is linked to the city location, on both flanks of the Avilés estuary and includes: alluvial deposits, eluvial deposits, estuarine deposits and coluvial deposits (Fig. 1). Moreover, several areas containing diverse anthropic deposits were recognized, related to the industrial zones.

The anthropic deposits are part of the overburden in most cross sections analyzed (Fig. 1) and two main types are distinguished: blast furnace slag heap and heterogeneous materials. The first of these is a by-product obtained in steel making and is inter-layered with muds and clay soils. The other deposit is formed by grains of diverse origins and is characterized by irregular internal structures and a low selfstability. Both kinds of deposits are no more than $3 \mathrm{~m}$ in thickness.

The alluvial deposits, which are modeled in the Section I and Section II (Fig. 2a and 2c), are composed of sands and gravels with intercalated clay layers. In these materials composition spatial changes are very common. They have average and maximum thicknesses of $5 \mathrm{~m}$ and $9 \mathrm{~m}$ respectively.

The construction of the micro-tunnel needed drilling through the bedrocks shown in Fig. 2b, 2d and 2f. The model of section II shows Permo-triassic Unit to be the only principal material present. The unit consists of red clays and marls with the former being more prevalent. Because of their likely weathering the mechanical behavior may be equivalent to that of soils.

Carbonate Jurassic Unit and Conglomeratic Jurassic Unit were crossed by the micro-tunnel in sections IV and VI, where the aforementioned rocks were found to be consistent and with thickness of $6 \mathrm{~m}$ and $4.5 \mathrm{~m}$ respectively. 


\section{Method of analysis}

A surface geological map of the effluent pipeline produced to a scale 1:5,000 (Fig. 1) was developed on the basis of the geological geotechnical exploration which entailed 23 rotary bored holes. Furthermore, a geological profile was also prepared using the information provided by the excavation works (Fig. 2). Finally, geotechnical characterization of the drilled subsoil was carried out taking into account the laboratory test results supplemented by field measurements (Table 1).

Seven transverse sections of the pipeline, whose location is shown in figure 1, were chosen for modelling in the $\mathrm{RS}^{2}$ software. At all the sections the minimum depth of the pipeline was $2 \mathrm{~m}$. The selection of sections targeted locations of potentially unstable zones having poor geotechnical parameters.

\section{Modelling method}

Both axisymmetric and plane strain analysis in the $R S^{2}$ program were implemented to provide a model to simulate reality as closely as possible. The combined use of these two analyses was necessary because of the fact the material ahead of the tunnel face was expected to deform before excavation, due to the influence of the continuous advancement of the cutter head on the local stress field.

Step 1 involved an axisymmetric analysis $\mathrm{RS}^{2}$ in order to perform the FE model to determinate the amount of deformation prior pipe jacking. Once this had been calculated, the stresses were accurately modelled with a two-dimensional plane-strain approach in $\mathrm{RS}^{2}$ (step 2), which suits the geometry of this type of problem.

\section{Axisymmetric analysis}

Axisymmetric modeling enables the analysis of 3-D excavation which is rotationally symmetric about an axis. The input is 2-D but the results apply to a 3-D problem. In this 
paper, the model analyzed represents the end of a pipeline of $0.75 \mathrm{~m}$ radius as shown in Fig. $3 \mathrm{a}$ and the axis of rotation is the vertical axis.

The surrounding rock was modelled an elastic-plastic material to conform to both the Mohr-Coulomb and a generalized Hoek-Brown yield criterion. The first criterion has been chosen in soils because failure envelopes in soils may approach to a linear behavior in contrast to rocks, where generalized Hoek-brown yield criterion has been selected. The physical and mechanical parameters as well as the field measurement results are shown in Table 1.

A free surface was adopted for the pipe end and length extent (Fig 3a). The upper left edge of the finite element model was specified as fixed in the $x$-direction and the bottom edge as fixed in the $y$ direction. This principle was introduced by Duncan (2000) (Fig. 3a).

The results from this analysis make it possible to determine the amount of displacement along the pipeline (Fig $3 b$ ) so that a curve is constructed by plotting the total displacement against the distance along pipeline (Fig. 3c). Taking into account that the pipeline was installed by jacking, the micro-tunnel face represents a support section. Thus the values of the total displacements at this section are required and have been output in Table 2. The table also shows the applied values of the softening factors (1$\beta$ ), in which the coefficient $\beta$ varies from 0 to 1 and is defined as the ratio of the stiffness of the material hitherto present in the tunnel space to the stiffness of the soil.

\section{Plane Strain analysis}

Since the rock ahead of the tunnel face began to deform before excavation, due to the stresses caused by the nearby excavation, a 2-D state of deformation was not reached until the tunnel face was several diameters away. This effect was simulated by gradually softening the material inside the tunnel using appropriate values of the parameter $\beta$. 
As done in axi-symmetric analysis, the surrounding rock was modelled as elastic-plastic and the ground surface specified as a free boundary. The right and left edges were considered fixed in the $x$ and $y$ directions as shown in Fig. 4.

Six stages were established where the modelled input properties of the material originally occupying the tunnel path (core material) were progressively adjusted to simulate the softening ahead of the tunnel face as the tunnel advanced. In the stage 1 , the material is the rock or soil in its in-situ condition. This involves the in-situ rock mass which means that it have the initial Young's modulus and have not suffered any deformation. In stages 2, 3 and 4 the core material parameter defined by (1- $\beta$ ) was increased in equal steps of $(1-\beta)=0.1$ (to represent gradually decreasing stiffness) as shown in Table 3 . In the $5^{\text {th }}$ stage (corresponding to a state where the pipe was now installed), the softening factor (1- $\beta$ ) of the core material was input as the value computed from axi-symmetric analysis (Table 2). The final stage (stage 6) corresponded to a stage where the core was now excavated and the full deformation realized (Fig. 4). In the $5^{\text {th }}$ stage, the concrete pipe was modelled as liner having a Young's modulus of $27 \times 10^{3} \mathrm{MPa}$, Poisson's ratio of 0.2 and thickness $0.14 \mathrm{~m}$.

\section{Groundwater}

From section III onward the pipeline was located below the water table (Fig. 2). To simulate the influence of the groundwater, a finite element seepage analysis assuming steady state flow conditions was performed. This model is based on a study presented by Shin et al. (2002a, b).

According to the in-situ tests performed at the site of the Avilés estuary effluent project, the permeability of the Permo-triassic and Jurassic Units were found to be very low (Lugeon coefficients $\leq 1$ ). In alluvial deposits, the values of permeability provided by Lefranc tests were less than $1 \times 10^{-7} \mathrm{~m} / \mathrm{s}$. In the rest of the Quaternary deposits, the 
permeability was indirectly estimated from granulo-metric data because field test data were not available. The highest value of permeability of $1 \times 10^{-5} \mathrm{~m} / \mathrm{s}$ was observed in the colluvial deposits.

The depth of the ground water table varied from $2.5 \mathrm{~m}$ to $3 \mathrm{~m}$. To simulate the drawdown of the water table a low permeability was assumed for the top layers. This was to create as low a recharge rate as possible. The micro-tunnel was assumed to have a permeable liner to allow water drainage into the tunnel face and thus the pressure at the surface of the pipe was set to zero. To compute the flow rate a vertical discharge section at a distance of $20 \mathrm{~cm}$ from the pipe was included (Fig. 5).

\section{Results}

\section{Stress distribution}

Figure 6a shows that the gravity stress contours start to be slightly perturbed ahead of the tunnel face. Plots of gravity stress versus distance are given in Figures $6 \mathrm{~b}-\mathrm{h}$, where the tunnel sections I-VII are also identified with labels. It is seen that higher stresses are concentrated at the bottom of the pipe and this is due to greater confinement. In all the transverse sections, the trend of variation of gravity stresses with distance is the same for the entire extent of the micro-tunnel. This is because the stress in the core is progressively transmitted to the excavation limit.

Sections IV and VI show the strongest growth of vertical stresses at the microtunnel boundary, due to the high unit weights of the carbonate and conglomerate units (Table1). It can be seen that the stress at section IV, which lies in the dolomites of the carbonate unit, increases by more than $100 \mathrm{kPa}$ from the in-situ state to the state when the pipeline is installed. 
In sections I, II, V and VII the gravity stresses reduce slightly at the floor of the tunnel when the material inside the micro-tunnel is excavated and the supporting pipe is installed (the last stage). This is because the concrete pipeline compensates the stress loss in the segment that previously had high stress concentration at the tunnel floor. Nevertheless, in transverse sections II, IV and VI, the support is not able to reduce the stress due to the high unit weight of the Mesozoic units being drilled through.

Another observation is that in section III there is a sudden change in the shape of the gravity stress contour at the micro-tunnel floor, owing to the close proximity to the bedrock boundary. This response causes perturbation of the normal distribution in the pipeline surroundings.

\section{Displacements}

The displacement of each monitoring point for pipe jacking in the 5 transverse sections is shown in Fig. 7. It can be seen that the settlement on the surface increases from the intact soil mass until the tunnel face. The maximum settlement is reached at the position of installation of the pipeline and is less than $1 \mathrm{~mm}$ (which is a small displacement) except in section VII where the subsidence reaches $1.2 \mathrm{~mm}$ (Fig. 7). Table 4 lists values of the maximum surface subsidence and volume losses due to the tunnel excavation. The volume loss is calculated by dividing the volume change due to surface divided by the volume of the excavation. As seen in Table 4, the section VII also has the greatest volume loss $(0.88 \%)$ due the excavation. Sections II, V and VII show higher ground subsidence due to the poor geotechnical characteristics of recent deposits present (Table 1). In section VII, an initial vertical displacement of $0.8 \mathrm{~mm}$ on the surface is observed. This is because of the thick blast furnace slag heap albeit having a very low unit weight. Under the material softening A and B monitoring points, the same movement trends are observed (Fig. 7a and 7b). An opposite trend is displayed by point $\mathrm{C}$, since in 
this case the vertical displacement is upward (therefore regarded as positive), implying inward displacement of the micro-tunnel walls (Fig 7c). Interestingly, at the same point $\mathrm{C}$ the trend appears to be an increase in the displacement rate, even though the pipeline is already installed. This is because of the effect of the weight of the concrete pipe when the tunnel bore is excavated, causing an apparent inward displacement.

\section{Groundwater}

There is an obvious drawdown of water table due to the drained boundary around the tunnel that represents the micro-tunnel face in this case study. Figure 8 also shows the pattern of flow of water into the excavation.

The highest steady-state flow rate of water is seen to occur in Section V (Table 5). This is because of the permeable nature of sands and gravels in the Talus deposits in this section. The measured flow rate is normal to the plane of the discharge section.

\section{Support loading}

The computed values of bending moments, axial forces and shear forces on the tunnel liner are shown in Table 6. The variations of shear force and bending moment at section I are also shown in Figure 9a and 9b. In order to demonstrate that both the bending moments and shear forces are well within the capacities of the micro-tunnel liner, a quick check based on elastic analysis of the $0.14 \mathrm{~m}$ thick liner was carried out. Assuming the liner to be unreinforced concrete, its ultimate moment of resistance per meter run was predicted using simple beam bending theory, adopting the tensile strength of the concrete as typically $1.5 \mathrm{~N} / \mathrm{mm}^{2}$ and ensuring this is not exceeded by the bending stresses. Also, a basic elastic solution for the distribution of shear stresses in the liner was adopted to show that the $0.14 \mathrm{~m}$ deep liner cross-section (treated as a unit width concrete beam having compressive strength of $40 \mathrm{~N} / \mathrm{mm}^{2}$ ), without shear 
reinforcement, will have a maximum shear stress equivalent to the value given in the last row of Table 6 .

\section{Conclusions}

A finite element simulation of the micro-tunnel installation was successfully carried out and the following conclusions may be drawn from the results obtained:

(1) The combined axisymmetric and plane strain analysis in the RS2 program provide a 2-D models but is able to simulate pipe jacking advance in 3-D. An accurate plane strain analysis was performed taken into account the amount of deformation at the tunnel face, which was previously calculated by axisymmetric analysis.

(2) At the ground surface, the maximum vertical displacement was found to be less than $1.3 \mathrm{~mm}$, thereby confirming that the pipe-jacking process was within normal safety limits. Sections within which pipeline was drilled in Quaternary deposits show a certain amount ground subsidence. Thus, the steepest of vertical displacement at ground surface from in-situ stage to the stage of pipe installation were in the thick coluvionar deposits. Subsidence was found to be heavily influenced by the thickness of material above tunnel and their unit weight and thickness.

(3) The highest increases in vertical stresses at the micro-tunnel boundary, from the in-situ up to the pipeline installation stage, were found to occur in the bedrock (Carbonate and Conglomerate units) due to its high unit weight.

(4) Within the soil deposits, there was a slight reduction in gravity stresses at the tunnel floor upon installation of the pipeline, owing to compensation of the 
stress loss. This behavior was not exhibited by tunnel sections formed through bedrock.

(5) The theoretical ultimate moment of resistance per meter and maximum shears stress in the concrete pipeline was more than 80 times higher than the model's liner values. Therefore all of them was within any of design factor of safety.

In summary, the paper has achieved its objectives of predicting the ground response to illustrate the patterns of ground subsidence and tunnel stresses. It is hoped that these primary findings will help designers in assessing tunnel stability and safety at different stages right from the in-situ conditions to the installed state of a micro-tunnel.

\section{Acknowledgements}

Authors are grateful to "Confederación Hidrográfica del Norte" to provide geotechnical data. This research received financial support from Banco Santander-University of Oviedo to do the researcher stay in Kingston University and "Programa de Profesorado Universitario (Ministerio de Educación del Gobierno de España).

\section{References}

Alonso, J. L., Marcos, A. and Suárez, A. 2009. Paleogeographic inversion resulting from large out of sequence breaching thrust: The Leon Faul (Cantabrian Zone, NW Iberia). A new picture of the external Thrust Belt in the Ibero-Armorican Arc, Geol. Acta., 7, 451-473.

Bennett, R. B., Guice, L. K., Khan, S. and Staheli, K. 1995. Microtunneling guidelines for trenchless technology, Ruston, LA, TTC Technical Report.

Chapman, D. N. 1999. A graphical method for predicting ground movements from pipe jacking, Proc. ICE-Geotech. Eng., 137, (2), 87-96.

Cheng, M. and Lu, Y. 2015. Developing a risk assessment method for complex pipe jacking construction projects, Automat. Constr., 58, 48-59. 
Cui, Q. L., Xu, Y. S., Shen, S. L., Yin, Z. Y. and Horpibulsuk, S. 2015. Field performance of concrete pipes during jacking in cemented sandy silt, Tunn. Undergr. Space Technol., 49, 336-344.

Descoeudres, F. and Egger, P. 1993. The effect of water seepage forces on the face stability of an experimental microtunnel, Can. Geotech. J., 30, (2), 363-369.

Díez López, J. R. 2001. Ingeotúneles tomo IV, Madrid, E. Gráfico.

Duncan, J.M. 2000. Factors of safety and reliability in geotechnical engineering, $J$. Geotech. Geoenviron. Eng., 126, 307-316.

Everaerts W. and Docavo Alberti, J. 2007. Toma Submarina mediante hinca de tubería para la granja de peces en Xove, Perfohinca, 1, 32-40.

Farrel, R. and Terry, D. 2015. Pipe-jacked canopy performance at Bond Street, London, UK, Geotech. Eng., 168, (3) 189-200.

Julivert, M. 1967. La ventana del Río Monasterio y la terminación meridional del Mando del Ponga, Trabaj. Geol., 1, 1-26.

Look, B. G. 2007. Handbook of Geotechnical Investigation and Design Tables, Taylor \& Francis, London,

Milligan G.W.E. and Norris P. 1996. Site-based research in pipe jacking-objectives, procedures and a case history, Trenchless Technol.Res., 11, (1), 3-24.

Oreste, P.P., Peila, D., Marchionni, V. and Sterling, R. 2002. Analysis of the problems connected to the sinking of micro-TBMs in difficult grounds, Tunn. Undergr. Space Technol., 16, 33-45.

Peila, D. 2001. Lo scavo di gallerie di piccola sezione con la técnica del microtunnelling. Conference: L'innovazione tecnologica nella perforazione e negli scavi, Tunnel \& Perforazioni, World of Tunnel drilling technology, Ferrara.

Schotmeyer, G. J., Hashimoto, T. and Shirakawa, J. 1999. Microtunneling in urban areas, 3-dimensional model and measurements, Proceedings of the 12th European Conference on Soil Mechanics and Geotechnical Engineering, 19791985, Amsterdam.

Senda, T., Shimada, H., Sasaoka, T. and Matsui, K. 2013. Behavior of surrounding soil during construction and its countermeasures using pipe jacking method in deep strata, Open J. Geol., 3, (2), 44-48. 
Shen, S. L., Cui, Q. L., Ho, C. E. And Xu, Y. S. 2016. Ground Response to Multiple Parallel Microtuneling Operations In cemented Silty Clay and Sand, J. Geotech. Geol. Eng., 142, (4), 04016001(1-11)

Shin, J.H., Addenbrooke, T.I. and Potts, D.M. 2002a. A numerical study of the effect of groundwater movement on long-term tunnel behavior, Geotechnique, 52, (6), 391-403.

Shin, J.H., Potts, D.M. and Addenbroke, T.I. 2002b. Three-dimensional modelling of NATM tunneling in decomposed granite soil, Geotechnique, 52, (3), 187-200.

Shou, K. J. and Chang, F. W. 2006. Analysis of pipe-soil interaction for a miniature pipejacking, J. Mech. 22, (3), 213-220.

Thompson, J.K. 1993. Pipejacking and Microtunneling, Blackie Academic and Professional, New York.

Torres Alonso, M. and Gutiérrez Claverol, M. 2005. Influencia de la geología en el diseño de infraestructuras de saneamiento. El plan integral de Avilés y su entorno industrial, Ing. Territ., 71, 76-83. 
Table 1. Mechanical parameters of sorrounding materials and support structure.

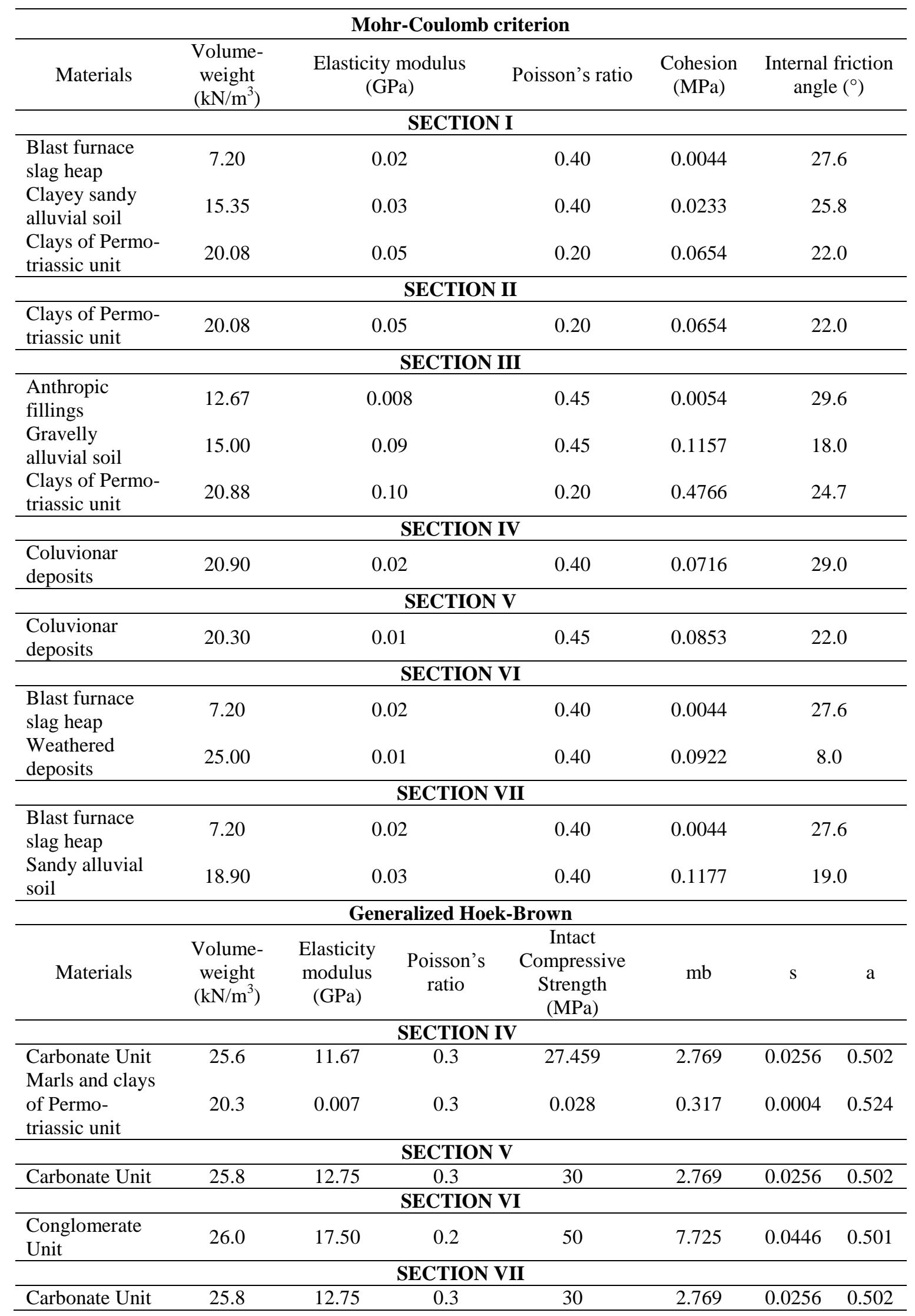


Table 2. Output of wall displacements at the pipeline face and at other sections behind the interface.

\begin{tabular}{cccc}
\hline $\begin{array}{l}\text { Transversal cross } \\
\text { sections }\end{array}$ & $\begin{array}{c}\text { Displacement at the pipeline face } \\
(\mathbf{m m})\end{array}$ & $\begin{array}{c}\text { Maximum total displacement } \\
(\mathbf{m m})\end{array}$ & $\mathbf{1 - \beta}$ \\
\hline I & 0.280 & 0.700 & 0.4 \\
II & 0.370 & 1.050 & 0.35 \\
III & 0.390 & 0.980 & 0.4 \\
IV & 0.005 & 0.010 & 0.36 \\
V & 4.340 & 10.800 & 0.4 \\
VI & 0.002 & 0.007 & 0.34 \\
VII & 0.270 & 0.700 & 0.38 \\
\hline
\end{tabular}

Table 3. Adjustment of stiffness values for each stage.

\begin{tabular}{lc}
\hline \multicolumn{1}{c}{ STAGES } & $\mathbf{1 - \beta}$ \\
\hline 1 (in-situ condition) & 0 \\
2 & 0.1 \\
3 & 0.2 \\
4 & 0.3 \\
5 (pile installed) & Value obtained by axisymmetric analysis. \\
6 & 1 \\
\hline
\end{tabular}

Table 4. Subsidence and volume loss due to the micro-tunnel excavation.

Transversal cross sections Subsidence (mm) Volume loss (\%)

\begin{tabular}{ccc}
\hline I & 0.46 & 0.192 \\
II & 0.85 & 0.310 \\
III & 0.28 & 0.163 \\
IV & 0.2 & 0.143 \\
V & 0.97 & 0.427 \\
VI & 0.14 & 0.121 \\
VII & 1.22 & 0.881 \\
\hline
\end{tabular}

Table 5. Volumetric flow across the discharge section (per $\mathrm{m}^{2}$ thickness of unit).

Transverse cross sections Flow rate $\left(\mathrm{m}^{3} / \mathrm{s}\right)$

\begin{tabular}{cl}
\hline III & $1.298 \times 10^{-7}$ \\
IV & $2.677 \times 10^{-6}$ \\
V & $9.362 \times 10^{-6}$ \\
VI & $1.852 \times 10^{-7}$ \\
VII & $6.661 \times 10^{-6}$ \\
\hline
\end{tabular}


Table 6: Maximum values of axial force, bending moment and shear force the concrete pipeline.

\begin{tabular}{cccc}
\hline $\begin{array}{c}\text { Transverse } \\
\text { cross sections }\end{array}$ & Axial Force (kN) & Bending moment $(\mathbf{k N m})$ & Shear Force $(\mathbf{k N})$ \\
\hline I & 4.7426 & 0.23007 & 0.87222 \\
II & 9.3386 & 0.15989 & 0.81300 \\
III & 11.385 & 0.17728 & 0.85779 \\
IV & 5.9574 & 0.005798 & 0.41460 \\
V & 10.843 & 0.054055 & 0.57584 \\
VI & 1.6397 & 0.001098 & 0.11922 \\
VII & 12.993 & 0.14546 & 0.94939 \\
\hline $\begin{array}{c}\text { Theoretical } \\
\text { capacity for }\end{array}$ & & 9.8 & 349 \\
liner & & & \\
\hline
\end{tabular}




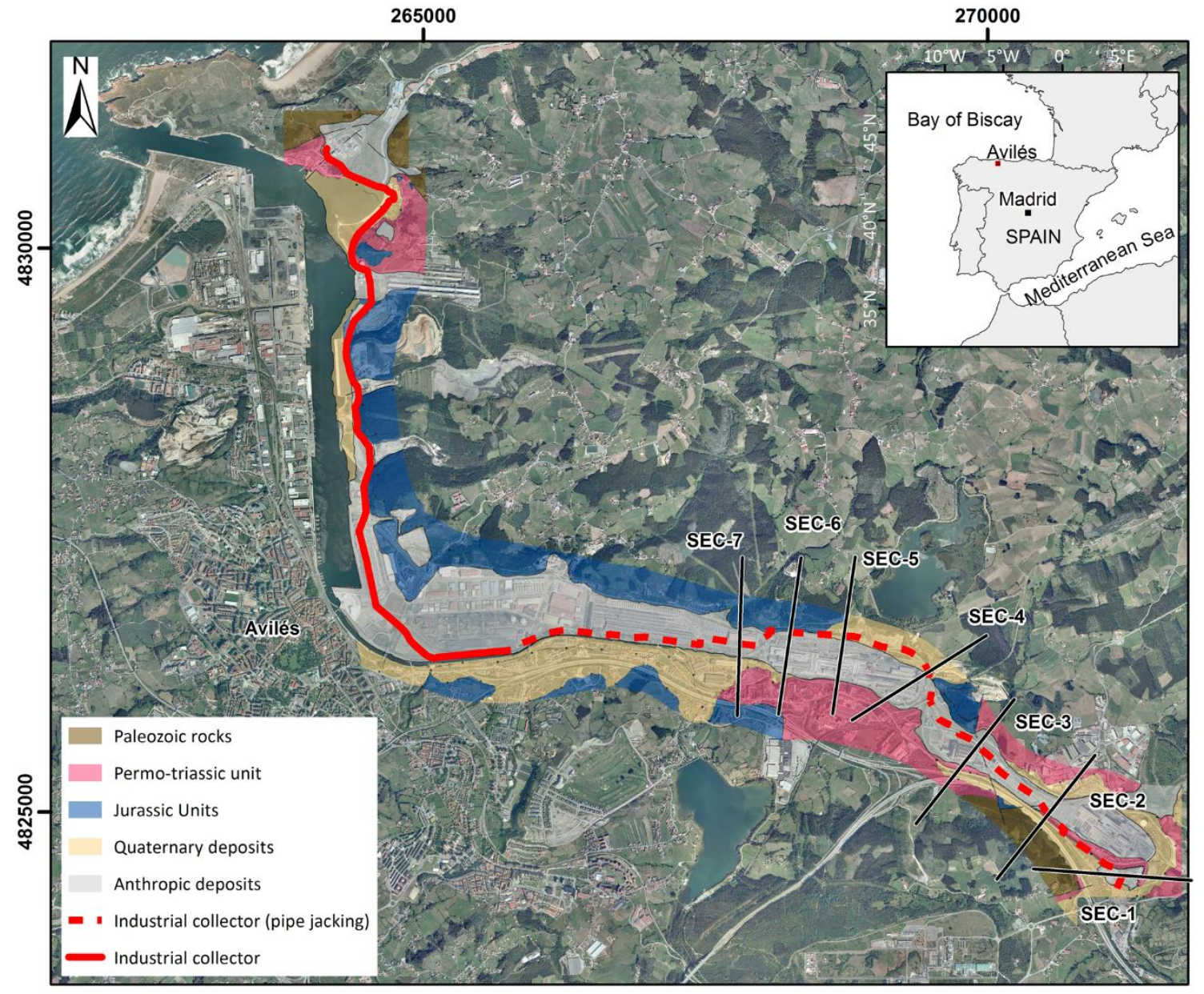

Figure 1. Map of the industrial effluent collector network (includes a surface detailing de location of the transverse sections analyzed). 

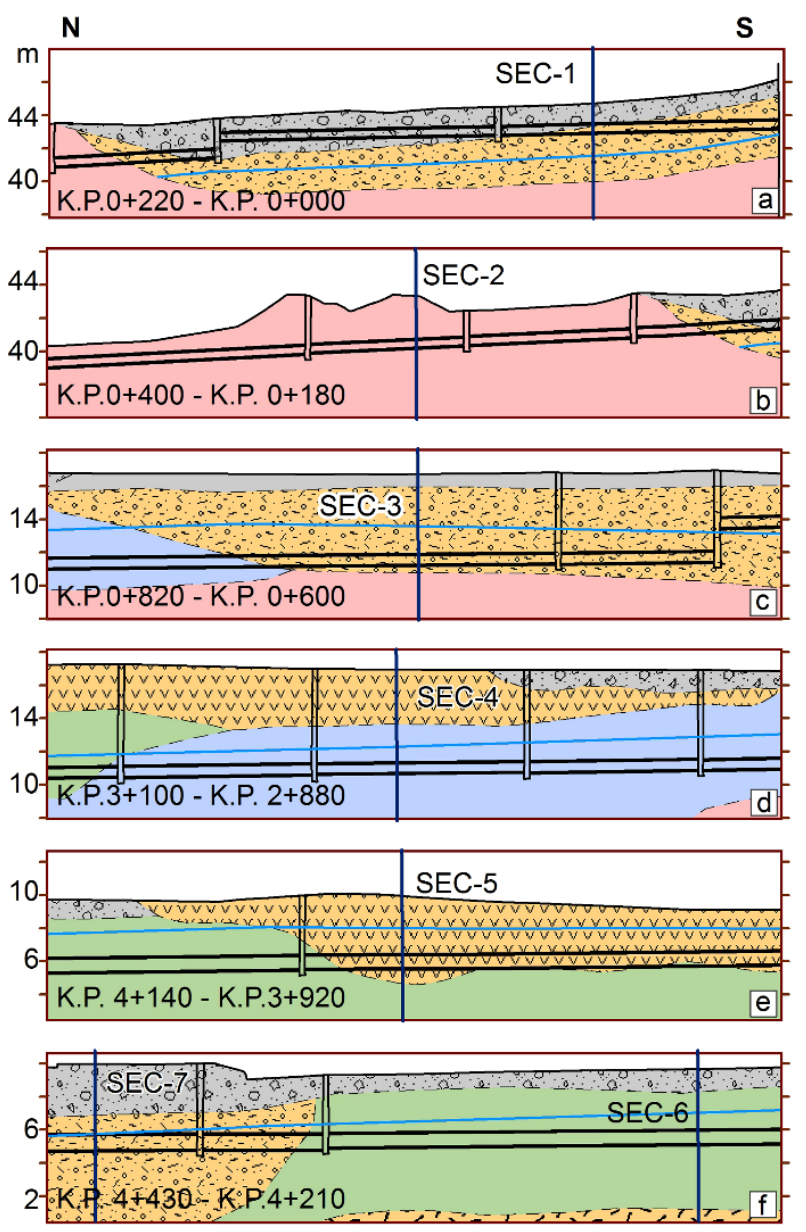

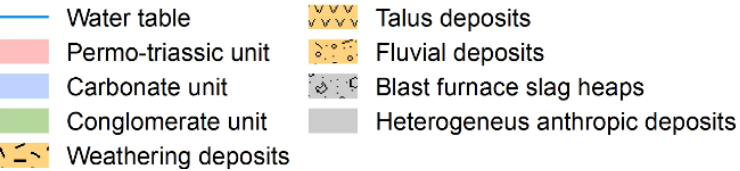

Figure 2. Profiles showing the main geological units. Black thick lines represent pipeline and jacking shafts. The seven analyzed sections are displayed as a blue line. 

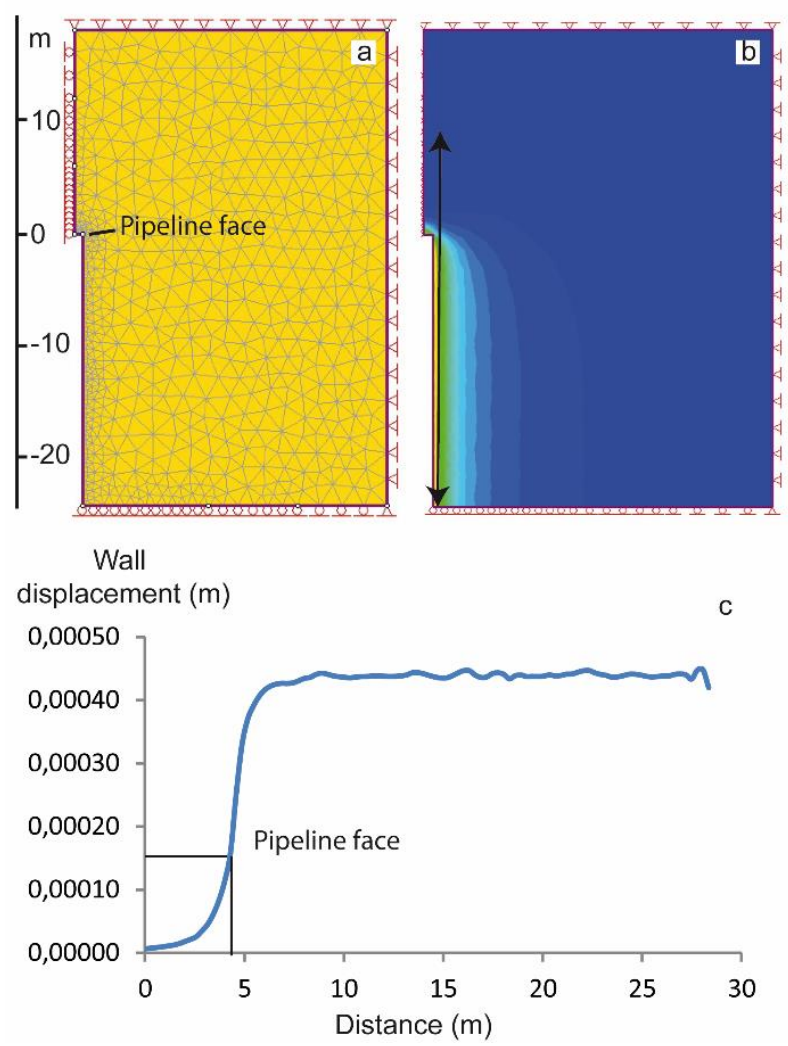

Figure 3. Axisymmetric model: a) model grid; b) Displacements contours around excavation in calculation model; c) Total displacement along the micro-tunnel and several meters ahead (black arrow).

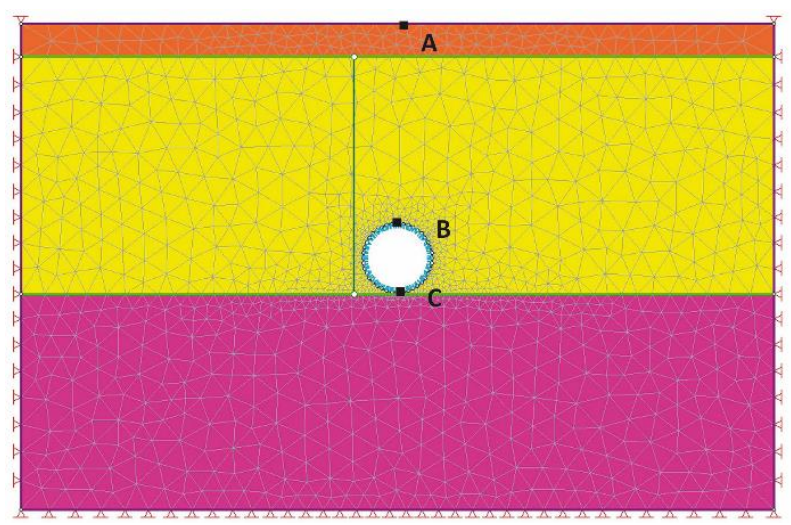

Figure 4. Model grid in plane strain analysis (monitoring points A, B, C as shown). 


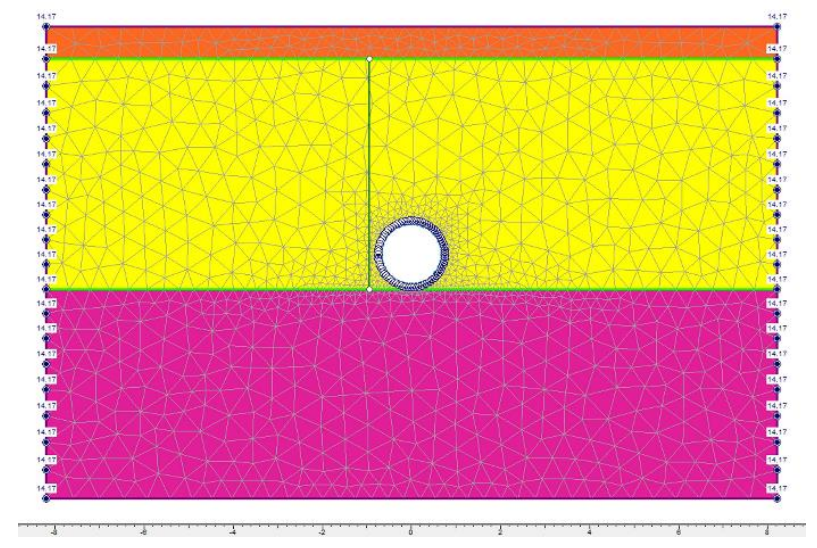

Figure 5. Groundwater conditions in SEC-III finite-element model. 

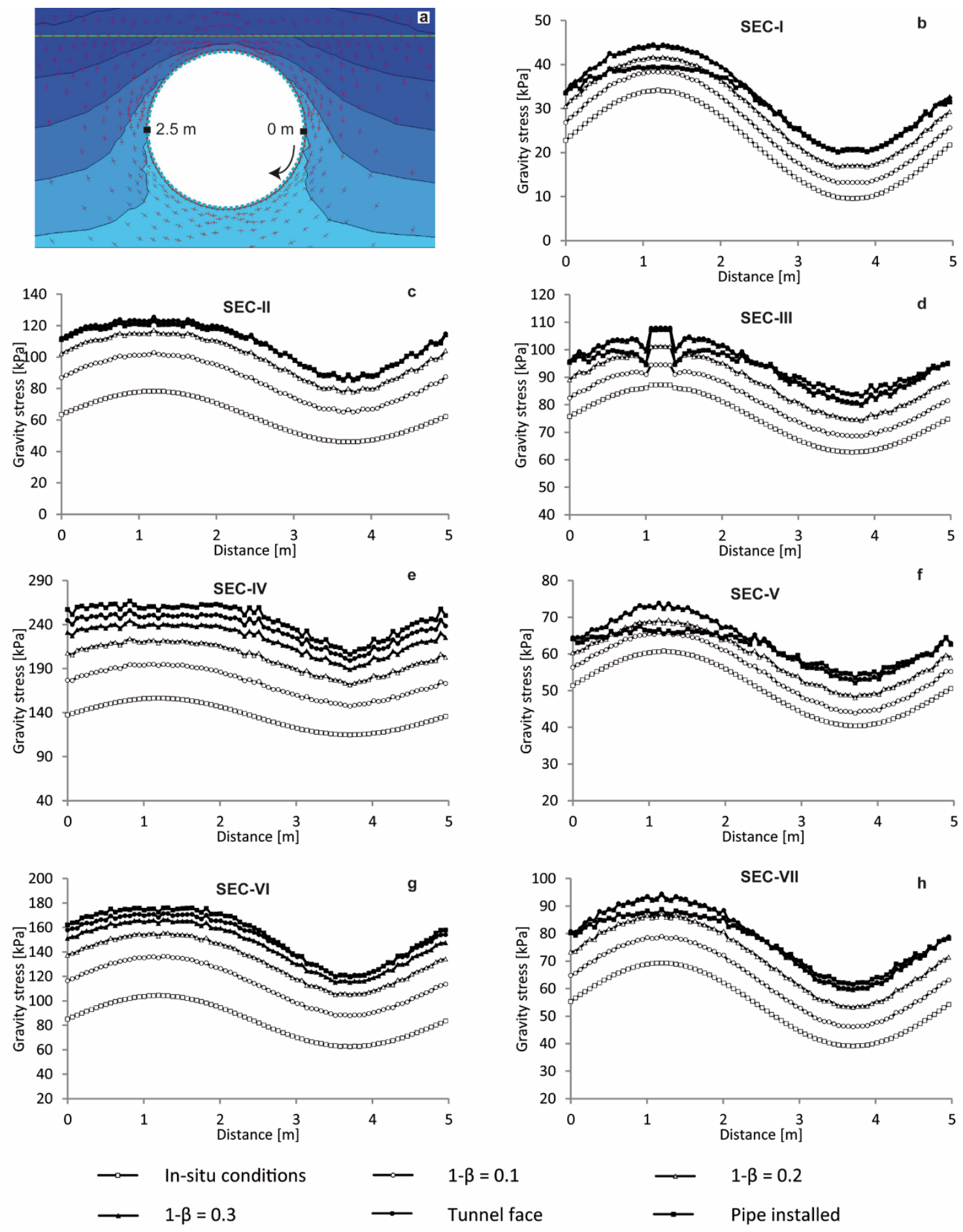

Figure 6. (a) Representation of the stress analysis results in stage 6 of transverse section I. Gravity stress along the micro-tunnel boundary in pipe-jacking advance: (b) SEC-I, (c) SEC-II, (d) SEC-III, (e) SEC-IV, (f) SEC-V, (g) SEC-VI, (h) SEC-VII. 


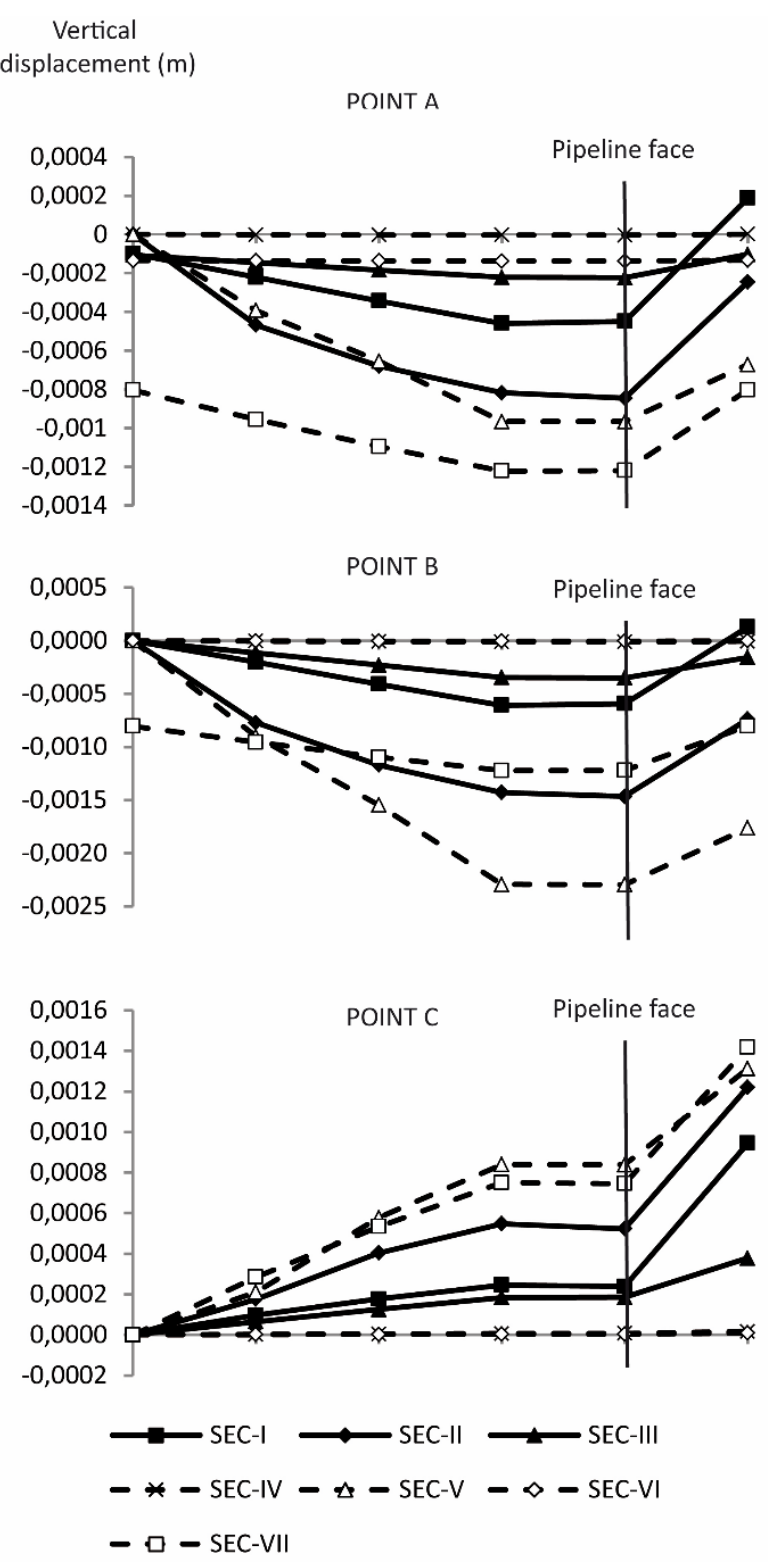

Figure 7. Vertical displacements of monitoring points during pipe jacking. 


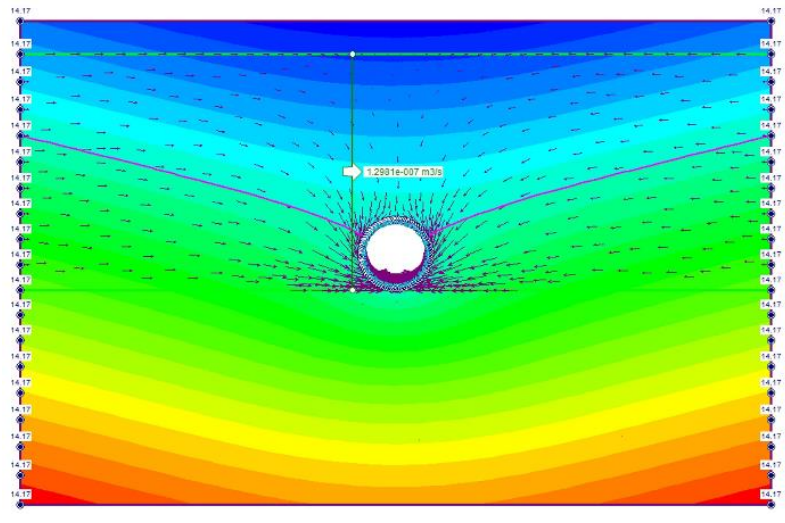

Figure 8. Pore pressure contours and flow vector at Section III (the green line represents the discharge section). 

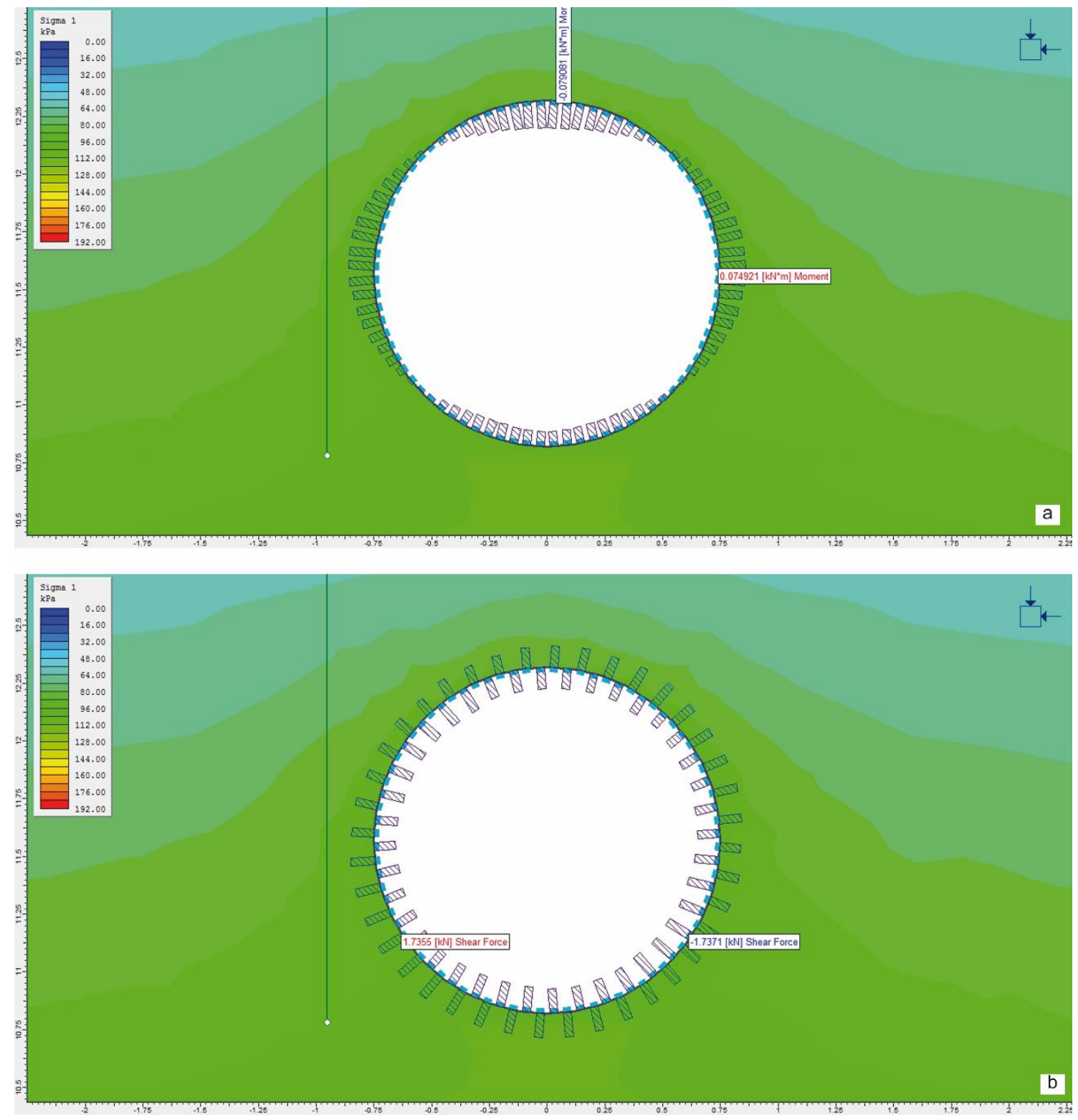

Figure 9. Bending moment values (a) and shear force values (b) along the concrete pipe. 


\section{Figure captions}

Figure 1. Map of the industrial effluent collector network (includes a surface detailing de location of the transverse sections analyzed).

Figure 2. Profiles showing the main geological units. Black thick lines represent pipeline and jacking shafts. The seven analyzed sections are displayed as a blue line.

Figure 3. Axisymmetric model: a) model grid; b) Displacements contours around excavation in calculation model; c) Total displacement along the micro-tunnel and several meters ahead (black arrow).

Figure 4. Model grid in plane strain analysis (monitoring points A, B, C as shown).

Figure 5. Groundwater conditions in SEC-III finite-element model.

Figure 6. (a) Representation of the stress analysis results in stage 6 of transverse section

I. Gravity stress along the micro-tunnel boundary in pipe-jacking advance: (b) SEC-I, (c) SEC-II, (d) SEC-III, (e) SEC-IV, (f) SEC-V, (g) SEC-VI, (h) SEC-VII.

Figure 7. Vertical displacements of monitoring points during pipe jacking.

Figure 8. Pore pressure contours and flow vector at Section III (the green line represents the discharge section).

Figure 9. Bending moment values (a) and shear force values (b) along the concrete pipe. 